\title{
AUSENCIA DE UN DISCURSO SOBRE EL HOMBRE EN EL TRATADO DEL IOMBRE DE DESCARTES
}

Anna Gómez Rabal

Nuestro interés por el Tratado del Hombre de Descartes surgió al hacer una traducción de la obra, partiendo de la versión latina y comparándola con la versión francesa, ya que Descartes escribió, él mismo, las dos versiones. ${ }^{1}$

El título, Tratado del IIombre, encierra una cierta ambigüedad, pues desde las primeras palabras del autor vemos que el discurso no se va a referir al hombre, a nosotros, sino a unos hombres que, como nosotros, están compuestos por un alma y un cuerpo. Descartes hace dos promesas: una, describir el cuerpo, otra, describir el alma, siguiendo la regla que su método establece de "dividir cada dificultad en cuantas partes sea posible y en cuantas requiera su mejor solución."2 Acto seguido aclara Descartes cómo entiende que debe definirse el cuerpo en esos hombres-máquinas: el cuerpo es lo que les permite imitar todas nuestras funciones "que sólo proceden de la materia y que sólo dependen de la disposición de los órganos." 3 El estudio del cuerpo que interesa a Descartes es, pues, el estudio de esas funciones y nos hará una descripción puramente mecanicista; establece un paralelismo con las fuentes y otros tipos de máquinas, pero insistiendo en que las "máquinas" hechas por Dios serán infinitamente más complejas, más sutiles que las hechas por los hombres.

Las funciones del cuerpo son, a su entender, consecuencia del calor del corazón y del movimiento de la sangre. Hay en el corazón "un fuego sin luz", verdadero secreto de la vida animal en tanto que activa el movimiento de la sangre. Ésta riega todas las partes del cuerpo, provocando la activación de todas las funciones; llega, en especial, al cerebro, y allí las partículas más sutiles de ella se transforman en espiritus animales. Éstos, a su vez, provocan, al moverse, el trabajo de los nervios y los músculos. Todas las funciones del cuerpo son entendidas de manera mecánica y la vida sólo depende del calor del corazón; no hay otro secreto.

Seguidamente Descartes describe los cinco sentidos externos, que funcionan siguiendo todos ellos un proceso automático similar. Nos advierte que los sentidos de esta máquina se corresponden a los nuestros, y formula una hipótesis importantísima: la unión a esa máquina de un alma racional, de la que nos hablará, dice, más adelante. El alma de esa máquina percibirá el dolor, el frio, los sabores, colores... Podrá deleitarse con la música y, en todo semejante a la del hombre, podrá percibir cualidades que no se vinculan a un solo sentido y podrá equivocarse en sus percepciones.

Descartes da un paso más en su descripción: el alma de esos hombres también será capaz de experimentar sensaciones internas y sentimientos. Podrá concebir la idea de sed, de hambre, el deseo de comer un alimento concreto, sentir alegria o tristeza. Y esas distintas sensaciones y sentimientos se producen, de nuevo, gracias a las distintas cualidades de la sangre $y$, por ende,

1 La primera edición latina se publicó en Leiden en 1662; la segunda en Amsterdam en 1686. Esta uiltima es la que utilizamos, cotejándola con la edición francesa de la Pléiade, para nuesira traducción. La primera edición francesa es de 1664 .

2 Discurso def Mítodo, traducción de Manuel Garcia Morente, Madrid, Espasa-Calpe, 1987, p. 49 (Selecciones Ausiral).

3 Tratado del hombre, traducción de Ana Gómez Rabal, Barcelona, M.R.A., 1994, pp. 1-1t. 
de los espiritus animales. Por las diferencias de cualidades de esos espiritus se explican la bondad, el amor, la malignidad... Para ilustrar su demostración, el autor nos recuerda el mecanismo de los órganos de las iglesias.

En la última partc del tratado, Descartes explica, por la conjunción de una serie de factores (a saber, el continuo movimiento de los espiritus animales en el cerebro, la constitución y las distintas concavidades de éste y la inclinación cambiante de la glándula pineal, que él llama $\mathrm{H}$ - de la cual salen los espiritus-), la memoria, la imaginación y los movimientos de los miembros. Describe ahora los mecanismos y movimientos que permiten percibir una cosa y formarse la idea de esa cosa. La idea es lo que se dibuja en la glándula $\mathrm{H}$, sede de la imaginación y del sentido común, mientras que el cerebro es únicamente la sede de la memoria. La identificación de las máquinas con el hombre parece total. Y casi al final del tratado, Descartes anuncia que le queda algo por describir y explicar: el alma racional, pero antes, en un resumen tenso, recuerda con autoridad que todas las funciones descritas imitan "con la mayor perfección posible las acciones de un hombre de verdad" $y$ que todas ellas son fruto de la disposición de los órganos, la misma afirmación con la que, prácticamente, se iniciaba el tratado.

Asi acaba la obra. La promesa de hablar del alma racional se queda en el tintero. ¿Porqué?

1. ¿Se escuda, simplemente, en que, como no ha hablado del hombre hombre, sino de máquinas semejantes a nosotros, no corresponde hablar de lo que hace hombre al hombre? Ese argumento se ha ido acortando; la fisiologia mecanicista expuesta por Descartes no sólo ha sido explicación dual, para la máquina y para el hombre, sino que, en ciertos momentos, al olvidarse Descartes de las excusas y al cscapársele palabras como el pronombre "nos", 5 se ha convertido explícitamente en explicación del hombre.

2. ¿No le interesa exponer cómo funciona lo que es más propio del hombre? Sabemos que, para Descartes, el hombre se define por ser un ser de lenguaje. ${ }^{6}$ Incluso podemos deducir esa definición del texto, porque a través de la lectura del Tratado del Hombre podemos adivinar qué es lo que supone la existencia de un alma racional: tener conciencia de las ideas $y$, por consiguiente, ser poseedor del lenguaje. El hombre es cuerpo y alma. ${ }^{7} \mathrm{El}$ alma -cuya esencia es el pensamiento- permite tener conciencia de las representaciones, de las ideas, que provienen o de los sentidos o de la razón; las primeras, las ideas que provienen de los sentidos, están, en la obra, explicadas con suma claridad, pero las otras, las ideas llamadas "innatas" o "abstractas", hijas de la razón, quedan sin explicar. El alma, además, tiene conciencia de las pasiones y puede determinarlas mediante la voluntad; Descartes ha explicado la generación y funcionamiento de las pasiones, sin embargo deja de lado la explicación de la voluntad. Nos encontramos con que Descartes nos ha dado una explicación mecánica de las funciones mentales en tanto que dependen del cuerpo y ahi corta su discurso. Según palabras suyas, el conocimiento que tenemos de nuestro pensamiento precede al que tenemos del cuerpo y es incomparablemente más evidente; por lo tanto, quizás lo que él encontrara interesante, por ser lo realmente dificil, seria la descripción de todas las funciones resultan-

\footnotetext{
4 Idem, p. LXXVII.

5 Idem, p. XLV.

6 Discurso del Mésodo, parte quinta, p. 81: para reconocer que las miquiras no son hombres verdaderos el primer método es "que nunca podrian hacer uso de palabras u otros signos, componiéndolos como hacemos nosotros para declarar nuestros pensamientos a los demás."

7 Cf. Tratado del hombre, p. XI, donde Descartes compara el a!ma con el fontanero que dirige los movjmientos de las fuentes.
} 
tes de la disposición del cuerpo. La respuesta a su corte en el discurso sería, entonces, que la explicación del funcionamiento del pensamiento, del lenguaje, por evidente, no haría falta darla.

3. Se ha dicho que Descartes quiso escribir un tratado sobre el alma, quizá continuación de este discurso. Es una hipótesis plausible, pues, dada la meticulosidad de Descartes en sus razonamientos, uno es reticente a creer que, por la supuesta sencillez del tema, no trate aqui la cuestión del alma racional. El lector, no obstante, queda con una cierta desazón ante la tensión y el "suspense" que ha creado Descartes con sus continuas promesas de hablarnos del alma racional. Desde el principio nos ha inculcado la idea de que Dios dará alma a la máquina, pero, al mutilar su discurso, ni siquiera se justifica diciendo, para no hablar del lenguaje, que, como Dios es el creador de la máquina y el que le otorgara el alma, no hay que buscar otras explicaciones. Es más, su resumen final puede aparecer como no inocente, ya que permite al lector dudar del hombre tal como lo concibe Descartes, y preguntarse si Dios es indispensable en el hombre racional: voluntariamente o no, Descartes al dejar pendiente la explicación última, y habiendo dado a la obra el título de Tratado del Hombre, deja una puerta abierta a todas las elucubraciones posibles. 